\title{
Successful Surgical Repair and Perioperative Management of 6-Month-Old With Total Anomalous Pulmonary Venous Return in a Developing Country: Considerations for the Treatment of Pulmonary Hypertension
}

\author{
Lakshmi R. Gokanapudy, b, n, Kenneth E. Remyb, c, d, Sathappan Karuppiahe, f, \\ Eneida V. Melgar Humala ${ }^{\text {b, g }}$, Ibrahim Abdullah ${ }^{b, ~ h, ~ i, ~ M i c h a e l ~ D . ~ R u p p e ~}{ }^{b, j, k}$, \\ William S. Schechter ${ }^{b,}$, Robert Michler $^{\mathrm{b}, \mathrm{m}}$, Joseph D. Tobias ${ }^{\mathrm{b}, \mathrm{d}}$
}

\begin{abstract}
Total anomalous pulmonary venous return (TAPVR) is a rare congenital cardiac defect, accounting for $1.5-3 \%$ of cases of congenital heart disease. With prenatal ultrasonography, the majority of these patients are diagnosed in utero with definitive surgery performed during the neonatal period. However, as prenatal screening may not be available in developing countries, patients may present in later infancy. We present successful surgical repair of a 6-month-old infant with TAPVR who presented for medical care at 5 months of age in Lima, Peru. The late presentation of such infants and the limited resources available for the treatment of elevated pulmonary vascular resistance may im-
\end{abstract}

Manuscript submitted December 14, 2017, accepted January 4, 2018

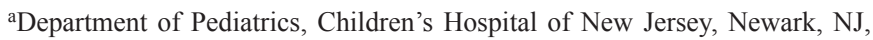
USA

bHeart Care International, Greenwich, CT, USA

'Department of Pediatrics, Washington University, St. Louis, MO, USA

dDivision of Pediatric Critical Care, St. Louis Children's Hospital, St. Louis, MO, USA

'Department of Anesthesiology and Pain Medicine, Nationwide Children's Hospital, Columbus, OH, USA

fDepartment of Anesthesiology and Pain Medicine, The Ohio State University College of Medicine, Columbus, OH, USA

gDepartment of Cardiothoracic Surgery, el Instituto Nacional de Salud del Nino, Lima, Peru

hDepartment of Surgery, University of Nebraska, Omaha, NE, USA

iDivision of Cardiothoracic Surgery, University of Nebraska, Omaha, NE, USA

${ }^{j}$ Department of Pediatrics, University of Louisville, Louisville, KY, USA

${ }^{\mathrm{k}}$ Division of Pediatric Critical Care Medicine, University of Louisville, Louisville, KY, USA

${ }^{1}$ Departments of Anesthesiology and Pediatrics, Columbia University, New York, NY, USA

${ }^{m}$ Department of Cardiothoracic and Vascular Surgery, Montefiore Medical Center and Albert Einstein College of Medicine, New York, NY, USA

${ }^{n}$ Corresponding Author: Lakshmi R. Gokanapudy, Department of Pediatric Cardiology, Washington University School of Medicine, Saint Louis Children's Hospital, 1 Children's Place, NWT Box 8116, St. Louis, MO 63110, USA. Email: Gokanapudy.L@wustl.edu

doi: https://doi.org/10.14740/cr651w pact successful surgical correction of such defects. The perioperative care of such infants in developing countries is discussed and strategies for managing postoperative pulmonary hypertension is reviewed.

Keywords: Total anomalous pulmonary venous return; Congenital heart disease; Pulmonary hypertension

\section{Introduction}

Total anomalous pulmonary venous return (TAPVR) is a rare congenital cardiac defect, accounting for $1.5-3 \%$ of cases of congenital heart disease (CHD) $[1,2]$. TAPVR results from failure of the formation of a common pulmonary vein from the left atrium with persistent connection of the primitive pulmonary vascular plexus to the common cardinal and umbilico-vitelline veins [3, 4]. TAPVR can be classified based on the anatomic defect (level of pulmonary venous drainage) or physiologic effect. Anatomic variants include supracardiac (40-50\%), intracardiac (15-20\%), infracardiac $(25-30 \%)$ or mixed type (5-10\%) while physiologic consequences include obstructive or non-obstructive venous drainage [3, 4]. Obstruction, which results in severe derangements immediately after birth, is usually due to the external compression from surrounding structures or reduced caliber of the internal lumen due to pulmonary vein hypoplasia or stenosis [5]. Identifying the drainage sites and level of obstruction is important for determining the surgical approach. Diagnosis is usually achieved by echocardiography and cardiac catheterization [6]. With the advent of improved prenatal ultrasonography, the majority of patients are diagnosed in utero. Although prenatal screening with ultrasonography and postnatal neonatal screening with pulse oximetry is generally effective in identifying the defect; such screening may not be available or routine in developing countries $[7,8]$.

If not identified during the newborn period with such screening, the age at which patients become clinically symptomatic and present to the hospital depends on the presence or absence of obstruction and the existence of intra-cardiac or ex- 
tra-cardiac shunts [9]. Clinical symptoms of congestive heart failure or hypoxemia, will not manifest until physiologic derangements occur related to obstruction of pulmonary venous return or the large left-to-right shunt. We report a 6-month-old infant with supracardiac TAPVR that presented in a developing country (Peru) at 5 months of age with the primary clinical symptoms of tachypnea and poor feeding. The late presentation of such infants is discussed and the perioperative challenges reviewed with emphasis on the prevention and treatment of elevated pulmonary vascular resistance in a developing country.

\section{Case Report}

The patient in this report was cared for during a cardiac surgery trip of Heart Care International (HCI) to El Instituto Nacional de Salud del Nino in Lima, Peru. HCI is a not-for-profit 501(c)(3) foundation based in Greenwich, Connecticut that has provided pediatric cardiology and cardiac surgery services in developing countries since 1994. HCI's goal is to not only provide primary cardiac surgical care, but also to train and educate host country health professionals. The majority of the equipment and supplies necessary for these surgical procedures is shipped into the country by HCI. Informed consent for surgery was obtained from the family and the HCI Board of Directors approved this report.

A 6-month-old, $5.5 \mathrm{~kg}$ former full-term male infant, who had been thriving and breastfeeding without difficulty, first presented for medical care at 5 months of age with new onset tachypnea and wheezing. During hospitalization for suspected pneumonia, a transthoracic echocardiogram was performed and revealed supracardiac TAPVR to an unobstructed confluence superior to the left atrium with a large atrial septal defect (ASD). In Peru, this cardiac lesion carries a very high mortality and rarely will children receive the option for surgical correction. This patient was scheduled for surgical repair as part of Heart Care International's twice annual pediatric cardiac surgical trip to Lima, Peru. On the day of surgery, a peripheral intravenous cannula (PIV) was placed to provide maintenance intravenous fluids and the patient was held nil per $o s$ for $6 \mathrm{~h}$. He was transported to the operating room where routine American Society of Anesthesiologists' monitors were placed. Anesthesia was induced with fentanyl $(5 \mu \mathrm{g} / \mathrm{kg})$ and ketamine $(1 \mathrm{mg} / \mathrm{kg})$ and neuromuscular blockade provided by rocuronium $(1 \mathrm{mg} / \mathrm{kg})$. Following anesthetic induction, a nasogastric tube was inserted and sildenafil $(2 \mathrm{mg} / \mathrm{kg})$ was administered. Maintenance anesthesia included sevoflurane (inspired concentration of 1-3\%) and fentanyl (total dose of $50 \mu \mathrm{g} / \mathrm{kg}$ ). Endotracheal intubation was performed with a 3.5 $\mathrm{mm}$ cuffed endotracheal tube. A second PIV, a left radial arterial cannula, and a double lumen central venous catheter (internal jugular) were placed. Repair of the TAPVR was performed using the previously reported "closed-vein" technique for primary sutureless repair [10]. Cannulation of the aorta, superior vena cava (SVC), and inferior vena cava (IVC) was performed along with placement of a vent in the vertical vein. The systemic temperature was maintained between $28-32$ ${ }^{\circ} \mathrm{C}$. The venous confluence was exposed through the retracted
ASD. The left atrial cuff was then sutured around the pulmonary confluence. Once this was complete, the confluence was opened and all four pulmonary venous orifices were identified. The vertical vein was ligated and the ASD was closed with an autologous pericardial patch. Prior to weaning from cardiopulmonary bypass (CPB), a loading dose of milrinone $(25 \mu \mathrm{g} / \mathrm{kg})$ was administered and an infusion started at $0.5 \mu \mathrm{g} / \mathrm{kg} / \mathrm{min}$. To maintain mean arterial pressure, an epinephrine infusion was initiated at $0.03 \mu \mathrm{g} / \mathrm{kg} / \mathrm{min}$. The patient was weaned from CPB without difficulty and heparin anticoagulation was reversed with protamine. Following weaning from $\mathrm{CPB}$, mild hyperventilation $\left(\mathrm{PaCO}_{2} 30-35 \mathrm{~mm} \mathrm{Hg}\right)$ was maintained with an inspired oxygen concentration $\geq 0.6$. The total CPB time was 99 min and aortic cross clamp time was $62 \mathrm{~min}$. The patient was transported to the intensive care unit (ICU) with the endotracheal tube in place, receiving mechanical ventilation. Ongoing sedation was provided by continuous infusions of fentanyl and midazolam. The epinephrine infusion was discontinued on postoperative day (POD) 1 and the milrinone discontinued on POD 2. The patient's trachea was extubated on POD 2 and the inspired oxygen concentration weaned to room air on POD 5. An echocardiogram on POD 1 revealed no obstruction to flow, no gradients across the pulmonary veins, and good myocardial function. Sildenafil was continued via the NG tube every $6 \mathrm{~h}$ for 7 days. The patient was eating well without complications and was discharged home on POD 7.

\section{Discussion}

TAPVR typically presents in infancy with the clinical signs and symptoms dependent on the site of drainage of the pulmonary veins and the degree of obstruction. Infracardiac TAPVR, in which the pulmonary venous plexus drains into the sinus venosus below the diaphragm, almost always presents with an obstructed picture as the sinus venosus constricts shortly after birth. If not identified by routine ultrasonography during pregnancy or post-natal pulse oximetry screening, the supracardiac and intracardiac unobstructed variants of TAPVR can present later in life, manifesting symptoms related to the large left-toright shunt with volume overload [11].

Infants with obstructed TAPVR appear critically ill, presenting at birth with marked cyanosis, tachypnea, dyspnea, hypoxemia, and metabolic acidosis. These children require urgent surgical repair [12]. In comparison, infants without obstruction, as was the case with our patient, may present later in infancy with signs and symptoms of congestive heart failure (tachypnea, poor feeding) related to volume overload and pulmonary over-circulation. Alternatively, signs and symptoms of pulmonary hypertension $(\mathrm{PH})$ may develop if the pulmonary venous return becomes obstructed. The relatively late presentation of our patient at 5 months of life can be attributed to an unobstructed supracardiac TAPVR with a large unrestricted ASD allowing ample mixing at the atrial level and unimpeded pulmonary venous return.

When infants present later in life, several factors may complicate the perioperative care including ongoing failure to thrive, congestive heart failure, respiratory insufficiency, and 
the potential for elevated pulmonary vascular resistance during the perioperative period especially following $\mathrm{CPB}$ when endothelial cell dysfunction may be present. The surgical technique used in our patient ("suture-less technique") is advantageous as it avoids the need for profound hypothermia and circulatory arrest with the potential for neurologic damage, limits postoperative bleeding, and has a decreased incidence of late restenosis which are particularly beneficial in a resource poor setting. Postoperatively, these patients are at a significant clinical risk for increased pulmonary vascular resistance and pulmonary hypertensive crisis $[13,14]$. Given the vasoreactive effects of alveolar oxygen and arterial carbon dioxide $\left(\mathrm{PaCO}_{2}\right)$ on the pulmonary vasculature, simple maneuvers include mild hyperventilation and the delivery of a high inspired concentration of oxygen. Other perioperative factors that may increase pulmonary vascular resistance include acidosis, hypothermia, and the surgical stress response.

Medications that decrease systemic pressure by direct negative inotropic effects or systemic vasodilatation should be avoided as the precipitous decrease in systemic vascular resistance may result in rapid decompensation and perioperative cardiac arrest. The importance of such issues are exemplified by the increased incidence of perioperative cardiac arrest in infants with CHD especially those with PH [13-15]. Intense analgesia with the use of a high-dose opioid technique with synthetic opioids (fentanyl or sufentanil) effectively controls the hyper adrenergic stress response and may effectively blunt pulmonary vascular reactivity [16]. In order to maintain systemic pressure and avoid hypotension, anesthesia was induced with ketamine. Although previously postulated to be contraindicated in the setting of $\mathrm{PH}$, recent data has demonstrated ketamine to be a safe and effective agent in this patient population as it maintains or increases systemic vascular resistance with little effect on PVR [17, 18]. A high-dose opioid technique with fentanyl was used intraoperatively with postoperative mechanical ventilation to optimize oxygenation and ventilation. Additionally, a postoperative fentanyl infusion was used to ensure adequate analgesia and sedation during the postoperative period during endotracheal intubation and mechanical ventilation.

Preexisting PH complicates the postoperative course in $2-7 \%$ of patients undergoing surgery for CHD [19-21]. Many of the episodes of PH can be effectively prevented by simple maneuvers of avoiding hypothermia, hypoxemia, acidosis, and agitation. Respiratory management plays a critical role in the management of PH. It is crucial to maintain adequate lung volumes and gas exchange while avoiding acidosis in the postoperative period when pulmonary edema, atelectasis, ventilation-perfusion mismatch, and bronchoconstriction may increase pulmonary vascular resistance (PVR). The maintenance of functional residual capacity (FRC) at baseline is crucial as either atelectasis or over-distention of alveoli can increase PVR. As such, positive end expiratory pressure should be titrated to maintain FRC. In our patient, sedation and ongoing ventilation were continued into the postoperative period to allow for the provision of intense analgesia and effective control of oxygenation and ventilation. $\mathrm{PH}$ may be exacerbated by airway instrumentation including tracheal suctioning $[16,22]$. A rapid increase in PVR can lead to right heart failure with a decrease in right ventricular ejection and failure. In the absence of a patent foramen ovale or atrial septostomy, right heart failure leads to a decrease in pulmonary blood flow, decreased pulmonary venous return to the left atrium, decreased cardiac output, and cardiac arrest. Treatment strategies for PHC include the administration of $100 \%$ oxygen and hyperventilion to correct acidosis and provide a moderate degree of hypocarbia $\left(\mathrm{PaCO}_{2} 25-30 \mathrm{~mm} \mathrm{Hg}\right)$ [23]. Once the $\mathrm{PaCO}_{2}$ is controlled, acidosis can be treated with the administration of sodium bicarbonate. Supplemental anesthesia can be administered especially if the crisis was precipitated by a noxious stimulus [24]. Cardiac output should be supported by the administration of fluid to increase preload and the use of inotropic agents as needed. Finally, various pharmacologic agents have been used for the treatment of $\mathrm{PH}$ including nitric oxide, phosphodiesterase inhibitors, prostacyclin analogues, and endothelin antagonists (Table 1) [25].

The time-honored and most commonly used pharmacologic therapy to treat or prevent postoperative $\mathrm{PH}$ following surgery for CHD remains inhaled nitric oxide (iNO) [2628]. However, this agent may be not available in developing countries. NO is administered via inhalation, thereby limiting its systemic effects and preventing decreases in systemic arterial pressure. NO increases intracellular cyclic guanosine monophosphate (cGMP) causing smooth muscle relaxation and vasodilation. NO binds to hemoglobin and is inactivated. Because it is a selective pulmonary vasodilator, easy to administer, and has a rapid onset, inhaled NO has become the primary therapy for postoperative PH. Once formed, intracellular cGMP is metabolized by phosphodiesterase type 5 (PDE). PDE type 5 inhibitors increase cGMP levels by preventing their breakdown, leading to vasodilatory effects on the pulmonary vasculature. However, these medications are generally administered via the oral or intravenous route and hence also have significant effects on the systemic circulation. Sildenafil, the main PDE type 5 inhibitor can be administered via the oral or intravenous route [29-31]. Oral sildenafil has been shown to attenuate rebound $\mathrm{PH}$ after iNO withdrawal and shorten the time to extubation and the length of time that intensive care is needed [29]. More recently, an intravenous preparation has been introduced into clinical practice and shown to effectively control PH following surgery for CHD [31]. Although currently approved for use in adults with $\mathrm{PH}$, sildenafil is used extensively off-label for the treatment of neonates, infants, and children with PH and may be used pre-emptively to mitigate pulmonary hypertensive crisis post-operatively as we attempted in this case. Despite such information, the United States Food and Drug Administration has recently cautioned against the long-term use of sildenafil in pediatric patients with $\mathrm{PH}$ due to an apparent increase in mortality during long-term therapy [32].

In an attempt to maximize pulmonary vasodilatation in this patient and to prevent $\mathrm{PH}$, we used a combination of intravenous milrinone and enteral sildenafil. While both agents may impact systemic blood pressure, their vasodilatory effects on the pulmonary vasculature generally outweigh their systemic effects [33]. In the event of a decrease in systemic blood pressure, inotropic support may be required and vasopressin is considered the agent of choice to increase systemic blood 
Table 1. Management of Perioperative Pulmonary Hypertensive Crisis

1. Correct hypoxemia and hypercarbia

2. Administer $100 \%$ oxygen

3. Hyperventilation

4. Maintain normothermia

5. Alkalization with the administration of sodium bicarbonate

6. Treat noxious stimuli by deepening the level of anesthesia or administering opioids such as fentanyl

7. After sedation and analgesia, provide neuromuscular blockade

8. Support cardiac output by administering fluid or inotropic agents

Vasopressin is preferable to adrenergic agents to increase mean arterial pressure without raising pulmonary artery pressure

9. Pharmacologic therapies

Nitric oxide

Increase intracellular cyclic GMP by inhibiting phosphodiesterase 5

Milrinone

Sildenafil (PR or NG)

Augment prostaglandin $\mathrm{G}_{2}$ (prostacyclin) system (systemic or inhaled)

Epoprostenol (Flolan ${ }^{\circledR}$ )

Treprostinil (Remodulin ${ }^{\circledR}$ )

Inhibit endothelin system

Bosentan

Miscellaneous agents

Nesiritide

levosimendan

pressure. In a preliminary study of 15 pediatric patients with $\mathrm{PH}$, the ratio of pulmonary-to-systemic vascular resistance decreased in three of five patients receiving phenylephrine, five of five patients receiving arginine vasopressin, and three of five patients receiving epinephrine [34]. In an effort to avoid the potential systemic effects of milrinone, investigational studies have reported its administration via aerosol, offering an alternative agent in settings where NO is unavailable $[35,36]$.

Prostaglandin $\mathrm{I}_{2}\left(\mathrm{PGI}_{2}\right)$ or prostacylin has recently seen increased use in the treatment of $\mathrm{PH}$. $\mathrm{PGI}_{2}$ stimulates the cAMP pathway to increase pulmonary vasodilation. These agents are available for systemic or inhalational administration. Children with $\mathrm{PH}$ show diminished $\mathrm{PGI}_{2}$ synthase expression in lung vasculature, thus intravenous $\mathrm{PGI}_{2}$ has become one of the standards of treatment of severe $\mathrm{PH}$ with right heart failure, showing improvements in long-term survival and quality of life. However, the intravenous route is generally used only for long-term therapy and not in the acute treatment or prevention of a PH crisis during the perioperative period. Although these agents have been shown to improve survival, their long-term administration may be cumbersome. Epoprostenol (Flolan ${ }^{\circledR}$ ) requires continuous infusion without interruption via a central line, given its half life of 5 - 6 min. Treprostinil (Remodulin ${ }^{\circledR}$ ) has a longer half-life $(4 \mathrm{~h})$ and is administered by continuous subcutaneous administration. The inhaled $\mathrm{PGI}_{2}$ analog, iloprost (Ventavis ${ }^{\circledR}$ ), on the other hand is administered as a nebulization at $3-4 \mathrm{~h}$ intervals, and has the advantage of causing selective pulmonary vasodilation without affecting systemic blood pressure [37-39]. Given their rapid responsiveness and limited systemic effects, these agents may have a role in the treatment of an acute PH crisis. Endothelin 1 is a potent vasoconstrictor with several receptor subtypes on vascular smooth muscle. Bosentan is the main endothelin receptor antagonist in use; however, other agents that provide more selective receptor antagonism have recently been introduced for clinical care [40]. Bosentan is administered orally, lowers pulmonary vascular resistance, and improves exercise tolerance with long-term administration. However, our experience has demonstrated that these agents (prostaglandin analogues and endothelin antagonists) are generally not available in developing countries.

In summary, we offer a potential clinical pathway for the management of TAPVR in developing countries where resources may be limited. In developing countries and in particular, on medical missions, the standard pharmacologic agents (nitric oxide, prostaglandin analogues, and bosentan) may not be available. In general, pharmacologic therapy of PH is limited to enteral sildenafil (PR or NG), intravenous milrinone, and intravenous vasopressin. Pre-trip planning must include consideration of agents and techniques to treat $\mathrm{PH}$ taking into account cost, ease of transport, long-term therapy, experience of the host country healthcare team, and specific customs regulations which may impact on drug availability. Given the late presentation our patient, perioperative care was compounded 
by comorbid features of failure to thrive, chronic congestive heart failure from volume overload, and the potential for postoperative PH. Unfortunately, the majority of similar patients will die in the absence of the availability of appropriate medical management for $\mathrm{PH}$ and surgical expertise to treat the lesion. While it was fortuitous that Heart Care International was in the country at the time of presentation of this infant, the management of these patients is difficult in any country. Management of these patients is particularly difficult with limited pharmacologic agents and especially with the scarcity of advanced pharmacotherapies such as inhaled nitric oxide (Table 1). A thorough understanding of cardiopulmonary physiology including respiratory mechanics, acid-base interactions, pulmonary vascular reactivity, and cardiovascular physiology by a multidisciplinary team (cardiothoracic surgeons, intensivists, anesthesiologists, and cardiologists) will optimize patient outcomes and can be shared with colleagues in developing countries [41-44].

\section{References}

1. Michielon G, Di Donato RM, Pasquini L, Giannico S, Brancaccio G, Mazzera E, Squitieri C, et al. Total anomalous pulmonary venous connection: long-term appraisal with evolving technical solutions. Eur J Cardiothorac Surg. 2002;22(2):184-191.

2. Karamlou T, Gurofsky R, Al Sukhni E, Coles JG, Williams WG, Caldarone CA, Van Arsdell GS, et al. Factors associated with mortality and reoperation in 377 children with total anomalous pulmonary venous connection. Circulation. 2007;115(12):1591-1598.

3. Sano S, Brawn WJ, Mee RB. Total anomalous pulmonary venous drainage. J Thorac Cardiovasc Surg. 1989;97(6):886-892.

4. Wang JK, Lue HC, Wu MH, Young ML, Wu FF, Wu JM. Obstructed total anomalous pulmonary venous connection. Pediatr Cardiol. 1993;14(1):28-32.

5. Seale AN, Uemura H, Webber SA, Partridge J, Roughton M, Ho SY, McCarthy KP, et al. Total anomalous pulmonary venous connection: morphology and outcome from an international population-based study. Circulation. 2010;122(25):2718-2726.

6. Paquet M, Gutgesell H. Echocardiographic features of total anomalous pulmonary venous connection. Circulation. 1975;51(4):599-605.

7. Laux D, Fermont L, Bajolle F, Boudjemline Y, Stirnemann J, Bonnet D. Prenatal diagnosis of isolated total anomalous pulmonary venous connection: a series of 10 cases. Ultrasound Obstet Gynecol. 2013;41(3):291-297.

8. Munsi AS, Hussain M, Rima R, Biswas R, Sayeed A. Clinical profile of patients with total anomalous pulmonary venous return and their short term outcome in pediatric cardiac centre at Dhaka Shishu Hospital. Bangl J Med Sci 2015;14:270-273.

9. Ewer AK. Review of pulse oximetry screening for critical congenital heart defects in newborn infants. Curr Opin Cardiol. 2013;28(2):92-96.

10. Hammel JM, Hunt PW, Abdullah I, Duncan KF. "Closed- vein" technique for primary sutureless repair of anomalous pulmonary venous connection. Ann Thorac Surg. 2012;94(3):1021-1022.

11. Kanter KR. Surgical repair of total anomalous pulmonary venous connection. Semin Thorac Cardiovasc Surg Pediatr Card Surg Annu. 2006:40-44.

12. Bruno CJ, Havranek T. Screening for critical congenital heart disease in newborns. Adv Pediatr. 2015;62(1):211226.

13. Twite MD, Friesen RH. The anesthetic management of children with pulmonary hypertension in the cardiac catheterization laboratory. Anesthesiol Clin. 2014;32(1):157173.

14. Ramamoorthy C, Haberkern CM, Bhananker SM, Domino KB, Posner KL, Campos JS, Morray JP. Anesthesiarelated cardiac arrest in children with heart disease: data from the Pediatric Perioperative Cardiac Arrest (POCA) registry. Anesth Analg. 2010;110(5):1376-1382.

15. Warner MA, Lunn RJ, O'Leary PW, Schroeder DR. Outcomes of noncardiac surgical procedures in children and adults with congenital heart disease. Mayo Perioperative Outcomes Group. Mayo Clin Proc. 1998;73(8):728-734.

16. Hickey PR, Hansen DD, Wessel DL, Lang P, Jonas RA, Elixson EM. Blunting of stress responses in the pulmonary circulation of infants by fentanyl. Anesth Analg. 1985;64(12):1137-1142.

17. Friesen RH, Twite MD, Nichols CS, Cardwell KA, Pan Z, Darst JR, Wilson N, et al. Hemodynamic response to ketamine in children with pulmonary hypertension. Paediatr Anaesth. 2016;26(1):102-108.

18. Williams GD, Maan H, Ramamoorthy C, Kamra K, Bratton SL, Bair E, Kuan CC, et al. Perioperative complications in children with pulmonary hypertension undergoing general anesthesia with ketamine. Paediatr Anaesth. 2010;20(1):28-37.

19. Lindberg L, Olsson AK, Jogi P, Jonmarker C. How common is severe pulmonary hypertension after pediatric cardiac surgery? J Thorac Cardiovasc Surg. 2002;123(6):1155-1163.

20. Cobanoglu A, Menashe VD. Total anomalous pulmonary venous connection in neonates and young infants: repair in the current era. Ann Thorac Surg. 1993;55(1):43-48; discussion 48-49.

21. Yong MS, d'Udekem Y, Robertson T, Horton S, Dronavalli M, Brizard C, Weintraub R, et al. Outcomes of surgery for simple total anomalous pulmonary venous drainage in neonates. Ann Thorac Surg. 2011;91(6):1921-1927.

22. Hickey PR, Retzack SM. Acute right ventricular failure after pulmonary hypertensive responses to airway instrumentation: effect of fentanyl dose. Anesthesiology. 1993;78(2):372-376.

23. Morris K, Beghetti M, Petros A, Adatia I, Bohn D. Comparison of hyperventilation and inhaled nitric oxide for pulmonary hypertension after repair of congenital heart disease. Crit Care Med. 2000;28(8):2974-2978.

24. Gruber EM, Laussen PC, Casta A, Zimmerman AA, Zurakowski D, Reid R, Odegard KC, et al. Stress response in infants undergoing cardiac surgery: a randomized study of fentanyl bolus, fentanyl infusion, and fentanyl-mida- 
zolam infusion. Anesth Analg. 2001;92(4):882-890.

25. Ivy D. Pulmonary Hypertension in Children. Cardiol Clin. 2016;34(3):451-472.

26. Checchia PA, Bronicki RA, Goldstein B. Review of inhaled nitric oxide in the pediatric cardiac surgery setting. Pediatr Cardiol. 2012;33(4):493-505.

27. Curran RD, Mavroudis C, Backer CL, Sautel M, Zales VR, Wessel DL. Inhaled nitric oxide for children with congenital heart disease and pulmonary hypertension. Ann Thorac Surg. 1995;60(6):1765-1771.

28. Abman SH, Griebel JL, Parker DK, Schmidt JM, Swanton D, Kinsella JP. Acute effects of inhaled nitric oxide in children with severe hypoxemic respiratory failure. J Pediatr. 1994;124(6):881-888.

29. Namachivayam P, Theilen U, Butt WW, Cooper SM, Penny DJ, Shekerdemian LS. Sildenafil prevents rebound pulmonary hypertension after withdrawal of nitric oxide in children. Am J Respir Crit Care Med. 2006;174(9):10421047.

30. Humpl T, Reyes JT, Erickson S, Armano R, Holtby H, Adatia I. Sildenafil therapy for neonatal and childhood pulmonary hypertensive vascular disease. Cardiol Young. 2011;21(2):187-193.

31. Fraisse A, Butrous G, Taylor MB, Oakes M, Dilleen M, Wessel DL. Intravenous sildenafil for postoperative pulmonary hypertension in children with congenital heart disease. Intensive Care Med. 2011;37(3):502-509.

32. Abman SH, Kinsella JP, Rosenzweig EB, Krishnan U, Kulik T, Mullen M, Wessel DL, et al. Implications of the U.S. Food and Drug Administration warning against the use of sildenafil for the treatment of pediatric pulmonary hypertension. Am J Respir Crit Care Med. 2013;187(6):572-575.

33. Cohen AH, Hanson K, Morris K, Fouty B, McMurty IF, Clarke W, Rodman DM. Inhibition of cyclic 3'-5'-guanosine monophosphate-specific phosphodiesterase selectively vasodilates the pulmonary circulation in chronically hypoxic rats. J Clin Invest. 1996;97(1):172-179.

34. Siehr SL, Feinstein JA, Yang W, Peng LF, Ogawa MT, Ramamoorthy C. Hemodynamic Effects of Phenylephrine, Vasopressin, and Epinephrine in Children With Pulmonary Hypertension: A Pilot Study. Pediatr Crit Care Med. 2016;17(5):428-437.
35. Wang H, Gong M, Zhou B, Dai A. Comparison of inhaled and intravenous milrinone in patients with pulmonary hypertension undergoing mitral valve surgery. Adv Ther. 2009;26(4):462-468.

36. Haraldsson s A, Kieler-Jensen N, Ricksten SE. The additive pulmonary vasodilatory effects of inhaled prostacyclin and inhaled milrinone in postcardiac surgical patients with pulmonary hypertension. Anesth Analg. 2001;93(6):1439-1445, table of contents.

37. Rimensberger PC, Spahr-Schopfer I, Berner M, Jaeggi E, Kalangos A, Friedli B, Beghetti M. Inhaled nitric oxide versus aerosolized iloprost in secondary pulmonary hypertension in children with congenital heart disease: vasodilator capacity and cellular mechanisms. Circulation. 2001;103(4):544-548.

38. Khan TA, Schnickel G, Ross D, Bastani S, Laks H, Esmailian F, Marelli D, et al. A prospective, randomized, crossover pilot study of inhaled nitric oxide versus inhaled prostacyclin in heart transplant and lung transplant recipients. J Thorac Cardiovasc Surg. 2009;138(6):14171424.

39. Limsuwan A, Wanitkul S, Khosithset A, Attanavanich S, Samankatiwat P. Aerosolized iloprost for postoperative pulmonary hypertensive crisis in children with congenital heart disease. Int J Cardiol. 2008;129(3):333-338.

40. Abman SH. Role of endothelin receptor antagonists in the treatment of pulmonary arterial hypertension. Annu Rev Med. 2009;60:13-23.

41. Ryan A, Rosen DA, Tobias JD. Preliminary experience with nesiritide in pediatric patients less than 12 months of age. J Intensive Care Med. 2008;23(5):321-328.

42. Papoff P, Caresta E, Versacci P, Grossi R, Midulla F, Moretti C. The role of terlipressin in the management of severe pulmonary hypertension in congenital diaphragmatic hernia. Paediatr Anaesth. 2009;19(8):805-806.

43. Mishra A, Kumar B, Dutta V, Arya VK, Mishra AK. Comparative effect of levosimendan and milrinone in cardiac surgery patients with pulmonary hypertension and left ventricular dysfunction. J Cardiothorac Vasc Anesth. 2016;30(3):639-646.

44. Friesen RH, Williams GD. Anesthetic management of children with pulmonary arterial hypertension. Paediatr Anaesth. 2008;18(3):208-216. 